\title{
Focus on Profession: Teaching Insights Using a Technology in a SLA Classroom
}

\author{
Kamilya Karabayeva ${ }^{1}$ \\ ${ }^{1}$ Kazakh University of International Relations and World Languages, Almaty, Kazakhstan \\ Correspondence: Kamilya Karabayeva, Kazakh University of International Relations and World Languages, \\ 050022, Muratbayev st., 200, Almaty, Kazakhstan.
}

Received: October 10, 2014 Accepted: November 19, 2014 Online Published: January 28, 2015

doi:10.5539/ies.v8n2p151 URL: http://dx.doi.org/10.5539/ies.v8n2p151

\begin{abstract}
Modern higher education requires the problem of development of professional value insights of a teacher of a new formation to be solved. One of the vital tasks of the national education is development of axiological resources of a teacher's individuality and his value system and insights. It should be noted that teaching means of development of a teacher's professional value insights can be represented by optimization of axiological resources for his professional development and educational institution's teaching traditions of creating necessary environment for teacher's axiological development, including the use of information and communication technologies in the educational process.

The article introduces an axiological pattern of teacher's professional self-development concept within the stages of the professional value system development as well as in the context of the teacher's personal individuality. It gives reasons for the use of information and communication technologies in developing the professional value insights of a teacher of the new formation.

The article discloses a deep analysis of the professionally-orienting values in the context of formation competences as learning outcomes within the implementation of information and communication technologies and methods in the educational process.
\end{abstract}

Keywords: professional value insights, an axiological pattern of professional self-development, an interactive whiteboard, a software product, a web quest

\section{Introduction}

Nowadays the educational process results in the objective need for focusing a teacher on development of party-to-party relationship in a teacher-student diad. This determines the increased researchers' interest for the issues of axiological teaching aspects.

In education axiology means a phenomenon of "value insights of teacher's activity" as specifics allowing a teacher to satisfy his own material and cultural requirements and guide his social and professional activity which should be focused on implementing of socially important goals (Kyryakova, 2011).

Researchers of a teacher's personal individuality place professional value insights development among the main lines of development of professional value self-consciousness. Thus, the contemporary education science considers the axiological approach as a methodological basis (Slastenin \& Chizhakova, 2003) and axiologization is assumed to be the main trend of development of modern higher education. At the same time, axiologization is:

- a way of implementation of the axiological approach in the educational process, a component part of education liberalization. Both in theory and in practice it is axiologization that becomes crucial in the structure and hierarchy of humanist values in the educational process where the core element is a personal individuality as the main value;

- a method aimed at development of personal creative and reflective value insights, the lack of which makes personal professional accomplishments, life viewpoint, proper professional outcomes and career promotion impossible;

- a scope of measures for educational process modernization which results in focusing of the educational process on the value insights (Kyryakova, 2010). 
Kryahtunov has defined an axiological pattern of teacher's professional self-development. Its theoretical basis comprises the concept that teacher's professional self-development is a process of adoption of a certain value insights system including such elements as value of a teacher's and a student's personal individuality and teacher's activity (Kryhtunov, 2002).

Trifonova has singled out the following stages of development of the teacher's value insights:

$\checkmark \quad$ a motivational stage related to elaborating a commitment to develop the professional value system of a teacher's individuality;

$\checkmark \quad$ a cognitive stage aimed at development of the cognitive sphere of teacher's professional self-consciousness;

$\checkmark \quad$ an affective stage, that is development of the emotional and axiological sphere of professional self-consciousness or professional personalization;

$\checkmark$ professional self-projection which consists in revision of new ways and methods of teacher's activity on the basis of realization of cognitive and axiological aspects of professional self-consciousness (Trifonova, 2013).

It is at the last, final stage that the means of information and communication technologies can be crucial for development of the professional value insights of a teacher of the new formation. And since teaching features of information and communication technologies rely on two crucial inherent functions (information and communication), they can be applied at any level of the educational system (Titova, 2009; Titova \& Filatova, 2010).

Integration of information and communication technologies into the process of teaching foreign languages is characterized by significant value-laden resources which provide not only effectiveness of the process of (teaching) education, but also development of the teacher's professional value insights. In view of means of information and communication technologies the ways and means are as follows:

$\checkmark \quad$ realization of teacher's personal motives for studying new means and methods of teaching;

$\checkmark \quad$ application of innovative methods of acquiring professional teacher's competences;

$\checkmark \quad$ using means of information and communication technologies as person-targeted educational technologies.

In the latter case the professional value system involves person-targeted communication which represents teacher's trust-based partnership with a student. At this:

$\checkmark \quad$ a teacher expresses sincere interest to opinions and statements of students ;

$\checkmark \quad$ a teacher's mark is objectified by methods of control tests; this leads to development of learner autonomy;

$\checkmark \quad$ a teacher can freely express his feelings and emotions with regard to the subject of communication. This result in establishment of a relationship system based on outspokenness, emotional intensity and mutual trust; development of empathy and empathetic listening.

This stated, let us address opportunities and problems related to the use in the educational process of some means and methods of information and communication technologies which can be used only during classes.

\section{The Body}

\subsection{Use of Interactive Whiteboards in the Educational Process}

It should be noted that the modern generation of students who have started their studies in the first decade of the XXI century differs from the previous one due to the fact that they have been growing up in the course of turbulent IT development processes. From childhood they are used to unassisted use of personal computers and Internet. Modern students can't imagine life without entertaining computer games, they are used to reading electronic books, constant use of cellular communication as well as scientific, common and entertaining Internet-resources.

Modern students prefer educational Internet-resources and digital books to printed ones. That is why intensification of their educational activity requires other methods and equipment than those applied in traditional education, i.e. presentation of educational material on traditional school boards (with chalk or markers) for demonstration of information and graphic material.

Attention of modern students virtually dwelling in the information space can be hold for a long time only by the same or similar electronic means which they are normally used to and which allow young people to find themselves in the familiar virtual and interactive information space and encourage them to make statements and comment what they hear as they do it in Internet social networks. 
An interactive whiteboard is one of the means of information and communication technologies which can be used during class hours and with regard to their capacities and effect are similar to common computerized communicators, pads, game consoles and home cinemas. According to Kalytin, it is a hardware-software complex consisting of main interconnected components (a desktop, a control computer, a projection device) and complicated software, including hardware-software tools used, for instance, for testing and academic ranking calculation (Kalytin, 2013).

In 1991 SMART Technologies Inc. presented the first interactive board in the world. It was the first interactive board providing sensor control of computer software and written notes feature in Microsoft Windows standard programs.

Students easily understand material presented with such boards. Increased dynamism of information flow generated by an interactive whiteboard doesn't seem to be a difficulty. They take to multimedia materials as well as websites with interest and eagerly use digital notes drawn up by teachers (Kalytin, 2012).

However teachers, especially experienced ones, have difficulties in the practical use of interactive whiteboards. This is caused by teachers' problems of personal nature and results from the following circumstances: difficulty in mastering new equipment and need of getting used to the innovative method of conducting classes and the new broadcasting culture, need of revising previous practice, studying new software products and constant creativity. All the above stated is accompanied by easy fatigability of a teacher during the work with an interactive whiteboard.

Besides nowadays in higher educational institutions common blackboards outnumber the interactive ones. And if a teacher conducts classes in different classrooms the most part of which is not equipped with interactive whiteboards, it will take him a long time to get used to the latter ones. That is why teachers often prefer not to use the entire scope of interactive whiteboards' features in order to avoid such difficulties.

However it is the emerging difficulties to be mastered that can stimulate a teacher to overcome them and establish the new professional value insights.

It is obvious that the study of the methods of work with an interactive whiteboard means primarily that a teacher should focus on mastering the main software product which controls an interactive whiteboard and backing software used for pattern recognition (handwriting recognition). The stated software also requires other skills used, for instance, in testing students, ranking calculation and etc. (Stivens, n.d.).

At the same time a teacher should be a skilled user of auxiliary programs which allow creating spectacular screenings, video and audio demonstrations. These are minimum requirements, since an interactive whiteboard provides demonstration of any software and certain files started on a PC.

All this can be a serious problem for teachers of liberal arts and time consuming: it takes much of their personal time and efforts.

Mastering an interactive whiteboard is related to professional focus of a teacher on overcoming difficulties that are caused by the need to get used and that are typical for teachers with conventional teaching methods which should be changed. Old, long-established habits are due to the difficulties which a teacher with long practice of teaching in a higher educational institution has in getting out of the old-fashioned, conventional style of teaching and auxiliary tools.

In traditional education a teacher and students have no intermediary since notes are made by hand and materials are voiced out.

As opposed to this, according to researchers' opinion (Hadadi et al., 2014), a teacher and students using an interactive whiteboard have several intermediaries. Firstly, the interactive whiteboard equipped with a control software product, secondly, an electronic pen with control buttons which can serve both as a common pen and as an intelligent one; thirdly, various software products with a vast range of digital educational materials. Each of the stated intermediaries creates certain constraints in the demonstration process since a teacher has to get used to the use of a new educational equipment: to an interactive whiteboard with a control panel and a desktop adapted for recognition of special strokes or gestures; to an electronic pen equipped with its own control system, to the use of software products and digital educational material. Besides, the interactive whiteboard allows automatic recording of everything that is displayed on its surface, including full video recording.

A teacher should not only master all the above stated equipment, but also necessary get used to it in order to apply it more efficiently, since the techniques of work with an interactive whiteboard is just partly similar to the work with a common PC, but is quite different in the whole. 
Besides there is an extra difficulty: apart from acquiring skills of creating infographics on an interactive board it is necessary to change the way and culture of broadcasting for modern students' class.

As researchers assume (Slay et al., 2008), development of a new culture of broadcasting consists in changing the style of conducting classes, since the use of an interactive whiteboard leads to changes of students' status during a class. From now on they become active participants of the educational process like of Internet social networks. Now students can take personal part in infographics creation on an interactive whiteboard, in teleconferences with colleagues, creation of personal demonstrations, commenting digital notes of a teacher, including published comments of their mates.

All the above stated causes the necessity to change the traditional teacher's broadcast, leads him out of the framework of a spokesman and converts him into a party controlling the educational process and delegating much more independency to students than before.

Unfortunately, development of professional value insights caused by the need to master various software products, changing the culture of broadcasting and adoption of new methods in digital demonstrations is more time consuming. However environment of higher educational institutions does not yet press for encouraging teachers to master technological innovations related to the use of information and communication technologies. Higher educational institutions are actively reducing norms of teachers' working hours. Up to the present time extra time expenditures of teachers related to mastering new means of information and communication technologies and preparation of innovative digital educational material have not been taken into consideration.

According to some researchers (Stoica et al., 2011), another problem related to the use of interactive boards consists in easy fatigability, observed in a teacher due to acceleration of broadcasting pace, increased number of hand gestures in the course of work with a desktop surface, the need to constant figuring a procedure of work with an interactive board as well as due to increased time expenditures for preparation to classes.

At this during public speaking requires attention to narration and to listeners' feedback, as well as to sequence of commands operated in the course of the work with graphics and managing applications during demonstration.

Thus, constant self-control is needed and this leads to easy fatigability. Therefore the work with an interactive whiteboard requires more internal efforts from a teacher and this particularly concerns the early stage of mastering an interactive whiteboard. Frequent use of an interactive whiteboard significantly decreases fatigability but does not exclude it.

Teacher's focus on overcoming the further cluster of difficulties in the course of the use of interactive boards is related to complexity of software and techniques of using interactive whiteboards. In researchers' opinion (Jones et al., 2006), the complexity of software consists in the fact that a teacher has to be competent at operation principles of all application used in interactive whiteboards. Though the developers have been looking for generating an absolutely comprehensible interface and ultimately simplified technology of using all the electronic devices, a teacher (even one familiarly acquainted with popular software) has to spend much time to study facilities of unknown software, a new interface and a new technology as a whole.

Complexity of the technology consists in the fact that the work with an interactive whiteboard significantly differs from the work with a traditional school blackboard. In case of using an interactive whiteboard, drawing and writing a text are much more complicated, since each line is a separate figure which can be handled in various manners: it can be grouped, adjusted, transformed, deleted, rotated and etc. A text written on an interactive board can be converted into a printed one with necessary font type and size, justified and checked with regard to spelling. Graphic facilities are even more multiple: each simple geometric figure is transformed into an ideally even figure; a gallery of ready images allows their prompt use, however location of required images should be kept in mind; figures are deleted either by strokes, by special movements of fingers or an electronic pen. It is also important to get used to it (Katwibun, 2014).

Each new section of educational material represented in a class is accompanied by graphics which is not deleted but is always saved and becomes the next page of digital notes for students without which the use of an interactive whiteboard is less efficient.

Besides, directly before demonstration an extra difficulty arises: it relates to preliminary preparation of the equipment, since it is necessary to adjust and download a profile (a file of required settings). A teacher should have several profiles for different demonstrations. This leads to extra efforts, at this any malfunction before a lesson can negatively affect the teacher's mood and reduce his preparedness to the lesson.

As far as complexity of making notes on an interactive whiteboard is concerned, it consists in the fact that a software package excludes the possibility of using familiar devices - a mouse and a keyboard. Instead an 
electronic pen (or a finger) and a software keyboard are used. However, while mouse functions are entirely replaced by gestures (strokes) effected by a finger or an electronic pen, it is more difficult to replace a traditional keyboard by a soft one, since input speed of the software keyboard is much lower.

\subsection{A Webquest as an Educational Technology in a Higher Educational Institution}

A projects technology obtaining significant educational and developing potential which provides individualization of the educational process is considered to be another way to increase effectiveness of the educational process during practical training in a higher educational institution.

The use of project technologies in the educational process can not only intensify the interest for a subject studied by students but also to encourage implementation of teachers' self-cognition and increasing their self-rating. Arrangement of project activity with the use of information and communication technologies and filling educational information with personal, humanistic and professional value-charged contents refresh the axiological image of the teacher's job.

A Webquest is one of the variants of the project activity with the use of modern information and communication technologies.

According to Bents, F., a Webquest is an affirmative approach to the training process in the course of which students not only accumulate and arrange information received from Internet, but also focus their activity on solving an assigned task that is often related to their future occupation (Bents, $n . / d$.).

According to a description given by Bykhovsky an educational Webquest is worked out for the best Internet integration in different educational subjects at different levels of the educational process. In the researcher's opinion, the specifics of educational Webquests consists in the fact that information which students require for their work is found on different websites (Bykhovsky, n.d.).

In opinion of a developer of the webquest technology, Dodge, B., the educational technology of a webquest is a challenge task including elements of a role playing game; for its implementation Internet information resources are used (Dodge, 2001).

Dodge B. has set out a certain list of task types for Webquests (Dodge, 1997):

\begin{tabular}{|c|c|c|}
\hline Narration & Planning and projecting & Self-cognition \\
\hline $\begin{array}{l}\text { Demonstration of problem } \\
\text { understanding based on representing } \\
\text { materials received from different } \\
\text { sources in the form of a } \\
\text { presentation, a poster or a story. }\end{array}$ & $\begin{array}{l}\text { Making up a plan or a project on the } \\
\text { basis of given conditions }\end{array}$ & $\begin{array}{l}\text { Any aspects related to examination } \\
\text { of personality. }\end{array}$ \\
\hline Compilation & A creative task & An analytical task \\
\hline $\begin{array}{l}\text { Transformation of information } \\
\text { received from different sources into } \\
\text { a new form, for instance, creating } \\
\text { an online exhibition }\end{array}$ & \begin{tabular}{|l} 
Performing some creative work in a \\
given genre, for instance, writing a \\
play, making a video
\end{tabular} & $\begin{array}{l}\text { Search and systematization of } \\
\text { required information }\end{array}$ \\
\hline A puzzle problem & Consensus & Estimation \\
\hline $\begin{array}{l}\text { Drawing conclusions on the basis of } \\
\text { contradictory facts }\end{array}$ & Making up a decision on a challenge & Providing feedback \\
\hline Investigative reporting & Conviction & Scientific research \\
\hline $\begin{array}{l}\text { Non-biased presentation of } \\
\text { information with facts and contrary } \\
\text { opinions }\end{array}$ & $\begin{array}{l}\text { Persuading opponents or a neutral } \\
\text { party in one's own opinion }\end{array}$ & $\begin{array}{l}\text { Analysis of phenomena, discoveries } \\
\text { and factual material from original } \\
\text { network sources }\end{array}$ \\
\hline
\end{tabular}

A webquest can be carried out in various forms, the most popular of which are:

- making up a data base related to a webquest topic; 
- creation of a virtual world where project participants go by hyperlinks and model the environment;

- creation of a document analyzing a certain problem and further discussion of the analysis results;

- an on-line-interview with a virtual person, for instance, a famous politician or a scientist or a literary character and etc. (Bauer-Ramazani, 2005).

A Webquest has the following typical structure (Introduction into educational internet technology, 2009):

1) An introduction including a brief characteristic describing the main roles of participants in details, a scenario and a preliminary plan of work;

2) A main task describing the topic, detailing the result of work and a form of its presentation;

3) A list of necessary information resources (references) for task implementation;

4) A list of roles (at least 2), which students should play implementing a common task; at this, a plan of work and individual tasks are detailed for each participant of a Webquest;

5) A procedure of work which each participant should do during step-by-step task implementation;

6) Evaluation of the Webquest and a description of its criteria and parameters at a blank;

7) A conclusion describing experience received by the Webquest participants in the course of work over it.

At the initial (team) stage of work over a Webquest students are introduced to the main concepts of a collective task, the roles are distributed inside a team. At this one part can be played by 1 to 4 persons.

At the part-playing stage a team does an individual work targeted at the common result. According to the roles chosen, Webquest participants implement their tasks simultaneously. At this stage the aim is to find the required information concerning the stated topic, to draw out a site structure, create and refine website content. At this the results of each task are summed up and the team participants share the materials acquired in order to achieve the common goal, to design a website.

At the final stage of a Webquest under the teacher's direct guidance a team do the joint work in order to publish results of the study in Internet, draw conclusions and suggestions (Nikolaeva, 2002).

The result of a Webquest is its evaluation. So a detailed and relevant scale of evaluation criteria is the fundamental section of any Webquest. Since the Webquest is a complex task its evaluation is based on several criteria which should be defined by the type of a task and the form of results presentation. March, T., recommends to use 4-8 criteria, including evaluation of: task understanding, reliability of information used, its relevance with regard to the task topic, information consistency and structuredness, arguments' quality, originality, skills of team work, professional manner of results presentation and etc (March, 2003).

At this evaluation criteria should correspond to the type and aims of a task with regard to achieving a stated aim, quality of the work done and the process of its implementation, content and complexity of the task. When describing the evaluation parameters certain requirements should be satisfied: comprehensibility of the language used to describe evaluation criteria for participants, a definition of quantity-related difference of the parameters, a definition of importance of a criterion in the common evaluation.

Webquests can be divided into short-termed and long-termed. The aim of a short-term Webquest is to acquire competences and integrate them into the competences system. A short-term Webquest is implemented in one to three sessions. The objective of long-term Webquests is to deepen and specify competence in the stated topic. Upon long-term Webquest implementation a student acquires higher competence in analyzing the studied problem and masters the material so that to draw up tasks on this topic himself. A long-term Webquest is implemented within the term from one week to one-two months.

A Webquest can be related to one subject or be intersubject. In the latter case this work will be much less effective.

The use of Webquests is the most effective in small groups though there are individual Webquests to be executed by certain students. (Andreeva, 2004)

The use of Webquest technologies in the educational process makes relationship of a teacher and a student of the party-to-party nature, studying of a subject is less teacher-oriented and a student assumes increased responsibility both for competences received and the process of its acquiring since he has to arrange his timetable properly and choose the form of presentation of the results of his work. At this a teacher becomes rather an assistant or a mentor skillfully guiding a student in the course of his self-education. 


\subsection{Options of Using Other Teaching Internet-Materials in the Educational Process}

In the modern educational process the use of certain text, audio and video Internet content, and specifically foreign one, can be very effective. However, a demand has aroused for development of special teaching Internet-materials aimed at teaching students to work with Internet resources, in order that they will not be overwhelmed with the mass of various information of all kinds and use the information for educational and professional purposes. Unlike all other information and communication technologies, the teaching Internet materials are designed for educational purposes only.

Apart from Webquests, in English-language literature there are four other types of Internet-materials: a hotlist, treasure hunt, a subject sampler and a multimedia scrapbook.

The Hotlist is a list of Internet resources concerning a topic studied. It should just be compiled and it can be used in the education process. Searching information for the Hotlist doesn't take much time. For instance, you should enter a key word in a web search engine and you will get a required Hotlist.

Treasure hunt is much alike the Hotlist. It consists of links to different websites concerning a topic studied. The only difference is that each link includes questions referred to site content. A teacher can use these questions to guide students' searching activity. At the end of Treasure hunt students can be asked one more general question to find out whether they understand the topic as a whole. A detailed answer to this question should include answers to the previous more particular questions concerning each of the websites.

The Multimedia scrapbook is a kind of a gallery of multimedia resources. It involves links to text websites, photos, audio and video clips, graphic information and currently the most popular animated online tours. All scrapbook's files can be downloaded and used as information and illustrative material in studying a certain topic.

A Subject sampler contains links to text and multimedia Internet-materials (photos, audio and video clips, graphic information). But it differs by the fact that information should be received at emotional level. A student should not only get to know materials but offer his own opinion concerning the studied topic and give reasons to it. This increases students' activity and allows them to exchange opinions with their group mates.

\section{Conclusion}

Taking all the aforesaid into consideration, it can be concluded that the use of information and communication technologies in the educational process leads to establishment of new ways of the teacher's activity based on realization of cognitive and axiological sphere of professional self-consciousness and development of positive professional axiological self-rating of a teacher and a new system of axiological relations.

The use of information and communication technologies is necessary for the modern educational process. However it takes much more teacher's time and efforts than before, when technological changes have been less drastic. In order to overcome difficulties related to introduction of information and communication technologies, higher educational institutions have to stimulate and support enthusiastic teachers eager to study new information technologies increasing the level of university education.

Under the present conditions development of the professional value insights of a teacher of the new formation is thrown into sharp relief. In spite of good physiological and teacher training education, such concepts as the value of professionalism and professional dignity are often excluded from the value system.

Issues concerning development of the professional value insights of a teacher of the new formation take an important part in scientific researches caused by the need in a highly qualified teacher's personal individuality with the stable and professionally relevant value system.

The professional value insights of a teacher of the new formation are considered to be an integrated structure of professional self-consciousness of a teacher's individuality representing a multilevel integrative dynamic innovation and characterized by the stable hierarchy of the teacher's value insights which define the nature of professional activity.

The use of information and communication technologies in the higher educational process is a prospective direction of the teacher's activity which increases the level of teaching, changes the culture of communication and relationship of teachers and students. Such means and methods of information and communication technologies as the use of interactive whiteboards and the Webquest technology make education efficient and personally valuable. 


\section{References}

Andreeva, M. (2004). WebQuest technologies in development of communication and social and cultural competence. Information and communication technologies in foreign languages teaching. Abstracts of the First International Scientific and Training Conference, Moscow.

Bents, F. (n.d.). Using of WebQuests in educational activity. Retrieved August 20, 2014, from http://www.natalia-chimera.ru/view.php?id=42

Bykhovsky, Y. (n.d.). Educational WebQuests. Retrieved August 20, 2014, from http://www.iteach.ru/met/metodika/a2wn4.php

Bauer-Ramazani, Chr. (n.d.). WebQuests Resource Page, 1998-2005. Retrieved August 20, 2014, from http://academics.smcvt.edu/cbauer-ramazani/Links/webquests.htm

Dodge, B. (2001). A Rubric for Evaluating WebQuests, 2001. Retrieved September 16, 2014, from http://webquest.sdsu.edu/webquestrubric.html

Dodge, B. (n.d.). Some Thoughts About WebQuests, 1995-1997. Retrieved August 20, 2014, from http://webquest.sdsu.edu/about/webquests.html

Hadadi, A., Abbasi, H., \& Goodarzi, A. (2014, May 6). Developing Competencies for Using the Interactive Whiteboard to Implement Communicative Language Teaching in the English (Foreign Language) Classroom. Procedia-Social and Behavioral Sciences, 98, 618-620. http://dx.doi.org/10.1016/j.sbspro.2014.03.459

Introduction into educational internet technology: WebQuest. (2009). Retrieved August 20, 2014, from http://ikt-ylka.blogspot.com/2009/02/5.html

Jones, R., Peters, K., \& Shields, E. (2006). Providing for the next generation: adopting interactive whiteboards in $\begin{array}{lllll}\text { information } \quad \text { literacy } & \text { Informing. } & \text { 25-29. }\end{array}$ http://dx.doi.org/10.1016/B978-1-84334-243-4.50005-6

Kalytin, S. (2012). Electronic or digital? Problems of higher education: Proceedings of an International Scientific and Training Conference, edited by Gomza, T. Khabarovsk. Pacific National University publishing house.

Kalytin, S. (2013). An Interactive board. Practice of effective use in schools, colleges and universities. "Elective course. Industry-specific training” series. Moscow: SOLON-Press.

Katwibun, H. (2014). Using an Interactive Whiteboard in Vocabulary Teaching. Procedia-Social and Behavioral Sciences, 116, 674-678. http://dx.doi.org/10.1016/j.sbspro.2014.01.278

Kryhtunov, M. (2002). Professional self-development of a teacher: A theory, a model, a method: A monograph. Moscow: Moscow State Pedagogical University.

Kyryakova, A. (2010). Laws of development of axiological resources of a student's individuality. Progress of modern natural science, 11, 110-113.

Kyryakova, A. (2011). Value system of university education. Bulletin of the State University of Orenburg, 2, 27-33.

March, T. (n.d.). Criteria for Assessing Best WebQuests, 2002-2003. Retrieved September 16, 2014, from http://www.bestwebquests.com/bwq/matrix.asp

Nikolaeva, N. (2002). Educational WebQuests as a method and means of development of students' skills of information activity. Internet Education Issues, 7. Retrieved August 20, 2014, from http://vio.fio.ru/vio_07

Slastenin, V., \& Chizhakova, G. (2003). Introduction in pedagogical axiology. Moscow: Academy.

Slay, H., Siebörger, I., \& Hodgkinson-Williams, C. (2008). Interactive whiteboards: Real beauty or just "lipstick"? Computers \& Education, 3(51), 1321-1341. http://dx.doi.org/10.1016/j.compedu.2007.12.006

Stivens, I. (n.d.). Webinar "Formative assessment with interactive technologies. Part 1". Network education. Expert evaluation, textbooks. "NetEdu” website. Retrieved August 20, 2014, from http://netedu.ru/node/12163

Stoica, D., Paragina, F., Paragina, S., Miron, C., \& Jipa, A. (2011). The interactive whiteboard and the instructional design in teaching physics. Procedia-Social and Behavioral Sciences, 15, 3316-3321. http://dx.doi.org/10.1016/j.sbspro.2011.04.292 
Titova, S. (2009). Information and communication technologies in liberal arts education: Theory and practice. Moscow: P-Center.

Titova, S., \& Filatova, A. (2010). Web 2.0 technologies in teaching foreign languages. Moscow: P-Center.

Trifonova, I. (2013). Development of values resources of the individuality of a prospective teacher of foreign languages: A monograph. Izhevsk: Udmurtsky University publishing house.

\section{Copyrights}

Copyright for this article is retained by the author(s), with first publication rights granted to the journal.

This is an open-access article distributed under the terms and conditions of the Creative Commons Attribution license (http://creativecommons.org/licenses/by/3.0/). 